\title{
PENGARUH MANAJEMEN ASET TERHADAP OPTIMALISASI ASET TETAP PEMERINTAH KABUPATEN JAYAPURA
}

\author{
Moses Demetouw ${ }^{1}$ \\ jurnalmkd@gmail.com \\ Agustinus Salle ${ }^{2}$ \\ agustinussalle@gmail.com \\ Meinarni Asnawi ${ }^{3}$ \\ meinarni.asnawi@gmail.com
}

\begin{abstract}
This research aims to analyze the influence of asset management on the level of optimizing fixed assets (land and building) in local governments of Jayapura regency. Using purposive sampling method the sample to this research is 48 respondents. The variables are assets inventory, legal audit assets, asset valuation, and supervision and assets control.

According to the results using the multiple linear regression showed that individually inventory assets proven has a positive and significant impact on optimizing fixed assets (land and building) which means in accordance with hypothesis, individually legal audit assets not proved has a positive and significant impact on the level of optimizing assets fixed (land and building) which means not in accordance with hypothesis, individually asset valuation proven have had a positive and significant impact on the level of optimizing assets fixed (land and building), supervision and control assets proven have positive and significant impact on the level of optimizing assets fixed (land and building). While the simultaneous analysis results show that the four variables namely inventory of assets, audit legal assets, asset valuation, supervision and assets control proved significant I give positive response to the level of fixed ground asset optimality (land and building) this is proven by the value of $F$ count $>F$ table.
\end{abstract}

Keyword: assets inventory, assets legal audit, assets valuation, assets supervision and control, optimizing fixed assets (land and building).

\section{PENDAHULUAN}

Keuangan daerah adalah semua hak dan kewajiban daerah dalam rangka penyelenggaraan pemerintahan daerah yang dapat dinilai dengan uang, termasuk segala bentuk kekayaan yang berhubungan dengan hak dan kewajiban daerah.

Otonomi daerah dan perimbangan keuangan antara pusat dan daerah, secara implisit sebenarnya memposisikan pemerintah daerah agar mandiri dalam setiap aspek pembangunan, termasuk di dalamnya aspek pendanaan pembangunan daerah. Salah satu kriteria penting untuk mengetahui kemampuan daerah dalam mengatur dan mengurus rumah tangganya adalah kemampuan dalam bidang keuangan, oleh karena itu kemampuan untuk mengelola keuangan ini sangat besar pengaruhnya terhadap perkembangan suatu daerah.

\footnotetext{
${ }^{1}$ Alumni Mahasiswa Magister Keuangan Daerah Universitas Cenderawasih

2 Staf Dosen Jurusan IImu Akuntansi Fakultas Ekonomi \& Bisnis Universitas Cenderawasih

${ }^{3}$ Staf Dosen Jurusan IImu Akuntansi Fakultas Ekonomi \& Bisnis Universitas Cenderawasih
} 
Pemerintah daerah dapat menciptakan sumber pendapatan dengan mengoptimalkan pengolahan terhadap aset milik pemerintah daerah dengan cara melakukan langkah strategis untuk melakukan optimalisasi aset milik pemerintah daerah yang saat ini dikategorikan masih belum optimal serta mengevaluasi ketidakefisienan aset yang idle milik pemerintah daerah yang membutuhkan biaya operasional dan pemeliharaan yang besar. Kewenangan yang diberikan berkaitan pula dengan bagaimana pemerintah daerah mampu memaksimalkan kekayaan daerah yang dimiliki misalnya melalui pengelolaan aset.

Aset disini dapat diartikan sebagai barang/benda yang dapat dimiliki dan mempunyai nilai ekonomis (economic value), nilai komersial atau nilai pertukaran yang dimiliki atau digunakan suatu badan usaha, lembaga atau perorangan. Aset negara adalah barang tidak bergerak (tanah dan/atau bangunan) dan barang bergerak (inventarisasi) yang dibeli atas beban APBN dan perolehan lain yang sah, yang dimiliki/dikuasai oleh instansi lembaga pemerintah non departemen, badan-badan, tidak termasuk kekayaan yang dipisahkan dan bukan kekayaan pemerintah daerah.

Barang daerah adalah semua barang berwujud milik daerah yang berasal dari pembelian dengan dana yang bersumber seluruhnya atau sebagian dari APBD, dan atau berasal dari perolehan lainnya yang sah (Kepmendagri No.29 Tahun 2002 Bab I Pasal 1). Real property adalah hak perorangan atau badan hukum untuk memiliki dalam arti menguasai tanah dengan suatu hak atas tanah, misalnya hak milik atau hak guna bangunan berikut bangunan (permanen) yang didirikan diatasnya atau tanpa bangunan.

Pengertian ini perlu dibedakan antara penguasaannya secara fisik atas tanah dan/atau bangunan yang disebut real estate. Kepemilikannya sebagai konsep hukum (penguasaan secara yuridis), yaitu yang dilandasi dengan sesuatu hak atas tanah disebut real property (Siregar,2004:182). Berdasarkan beberapa penelitian terkait manajemen aset, masih terdapat banyak masalah dalam pengelolaan aset daerah.

Salah satu masalah utama pengelolaan barang (aset) daerah adalah ketidaktertiban dalam pengelolaan data barang (aset). Hal ini menyebabkan pemerintah daerah akan mengalami kesulitan untuk mengetahui secara pasti aset yang dikuasai/dikelolanya, sehingga aset-aset yang dikelola pemerintah daerah cenderung tidak optimal dalam penggunaannya (Siregar, 2004: 561).

Oleh sebab itu, pemerintah daerah harus benar-benar memahami apa sajakah yang harus dilakukan untuk mengoptimalkan aset-aset yang dimiliki guna 
meningkatkan Pendapatan Asli Daerah (PAD) khususnya dalam hal ini adalah aset tetap tanah dan bangunan.

Menurut Siregar (2004: 518-519) ada beberapa tahap manajemen aset yang dapat dilakukan guna meningkatkan aset-aset yang dimiliki yaitu inventarisasi aset, legal audit, penilaian aset, optimalisasi aset, serta pengawasan dan pengendalian aset, di mana jika kelima tahapan manajemen aset ini dijalankan dengan baik maka akan memberikan manfaat yang besar bagi pemerintah dalam meningkatkan efisiensi, efektifitas dan menciptakan nilai tambah dalam mengelola aset yang lebih tertib, akuntabel, dan transparan. Berangkat dari penjelasan di atas, maka tujuan penelitian ini adalah menganalisis pengaruh manajemen aset yang terdiri dariinventarisasi aset, legal audit aset, penilaian aset, pemanfaatan aset, serta pengawasan dan pengendalian aset terhadap optimalisasi aset tetap (tanah dan bangunan) milik Pemerintah Kabupaten Jayapura Provinsi Papua.

Lewes District Council (2005:2) mengatakan bahwa tujuan dari perencanaan manajemen aset adalah : (1) Memastikan efektivitas dan koordinasi kegiatan manajemen aset yang disusun pemerintah; (2) Mengawasi penggunaan dana dalam proses manajemen serta penggunaan aset property; (3) Memastikan bahwa permasalahan manajemen aset telah dibahas dalam pertemuan pengambilan keputusan sebagai dasar penyusunan rencana pelayanan; (4) Memahami batasan efektivitas, efisiensi serta mempertimbangkan kondisi ekonomi dalam menyusun manajemen/pengelolaan asset; (5) Membuat pola kerjasama pengelolaan aset dengan pihak ketiga atau organisasi lain yang mampu memenuhi kebutuhan masyarakat.

Schaefers (1999) melakukan penelitian terhadap perusahaan-perusahaan di Jerman tentang penerapan konsep Corporate Real Estate (CRE) Management. Penelitian ini memperlihatkan bahwa meskipun nilai maupun biaya aset-aset real estate menunjukkan jumlah yang signifikan, aset-aset CRE saat ini oleh perusahaan-perusahaan yang dijadikan sampel tetap dikelola secara serius.

Manajemen real estate yang efektif berarti manajemen yang beralih dari reaktif dengan proses pengambilan keputusan yang terdesentralisasi melalui organisasi, menuju kepada yang bersifat proaktif, komfrehensif dan manajemen secara luas dan menyeluruh serta didukung oleh informasi yang memadai dan tepat waktu serta komitmen dari top manajemen.

Schaefers juga menjelaskan bahwa kerangka konseptual manajemen aset real estate mencakup item-item karakteristik manajerial dan operasional manajemen aset real estate aktif yang meliputi sistem informasi real estate, sistem perencanaan real estate, sistem pengorganisasian real estate dan sistem 
pengawasan real estate. Manajemen aset real estate juga dipengaruhi oleh jenis perusahaan, ukuran perusahaan, sikap top manajemen, nilai aset, ukuran asset dan komposisi aset.

Penelitian ini menguji variabel inventarisasi, identifikasi, legalaudit dan penilaian terhadap optimalisasi aset tetap di Kabupaten Jayapura. Kerangka model dalam penelitian ini dapat digambarkan sebagai berikut ini.

Gambar 1.1. Model Penelitian

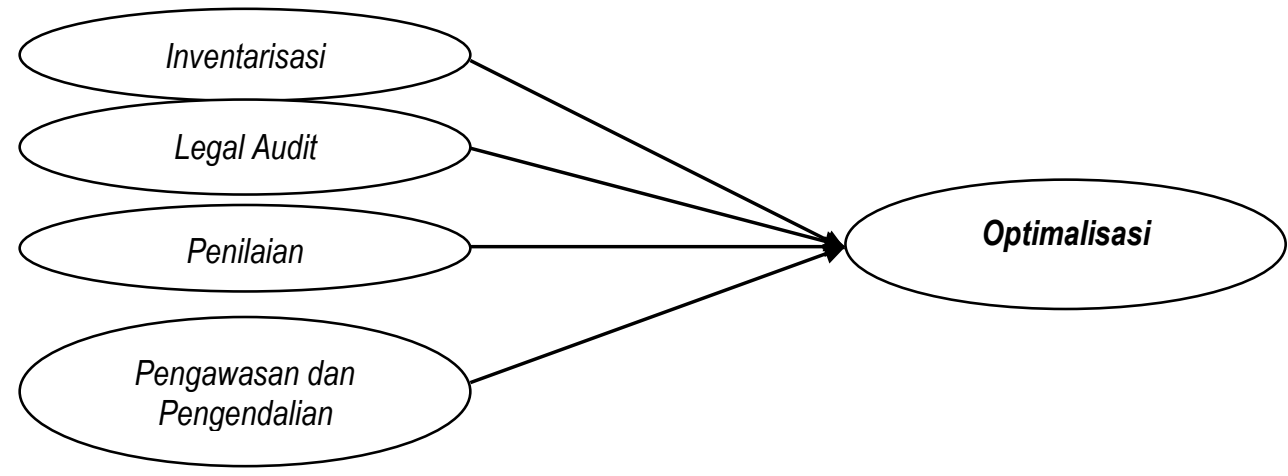

Sumber : Siregar (2004) diolah penulis, 2016

\section{METODE PENELITIAN}

Penelitian ini menggunakan data primer yang diperoleh melalui pengisian kuesioner dengan menggunakan aspek-aspek yang dianggap penting dalam pelaksanaan manajemen aset sebagai variabel independen adalah sebagai berikut : Inventarisasi, Legal audit, Penilaian, Pengawasan dan Pengendalian Aset.

\section{HASIL DAN PEMBAHASAN}

kuesioner yang telah disebarkan kepada 48 responden jumlah skor ideal atau skor tertinggi (SS) untuk seluruh item adalah sebesar $4560(5 \times 19 \times 48)$ dan jumlah skor terendah (STS) sebesar 912 (1 x $19 \times 48)$. Jawaban-jawaban yang telah diberikan oleh responden umumnya berada pada kriteria setuju.

Tabel 1.1 Rekapitulasi Jawaban Responden

\begin{tabular}{|c|c|c|c|c|c|c|}
\hline Variabel & \multicolumn{5}{|c|}{ Skala likert } & \multirow[t]{2}{*}{ Total } \\
\hline & 1 & 2 & 3 & 4 & 5 & \\
\hline Inventarisasi & 1 & 19 & 48 & 108 & 16 & 192 \\
\hline Legal audit & - & 12 & 51 & 125 & 4 & 192 \\
\hline Penilaian & - & 4 & 38 & 131 & 19 & 192 \\
\hline $\begin{array}{l}\text { Pengawasan \& } \\
\text { pengendalian }\end{array}$ & - & 2 & 14 & 117 & 11 & 144 \\
\hline Jumlah & 1 & 37 & 151 & 481 & 50 & 720 \\
\hline Total (skor x jumlah) & 1 & 74 & 453 & 1924 & 250 & 2702 \\
\hline$\%$ & 0,03 & 2,73 & 16,76 & 71,20 & 9,25 & 100 \\
\hline
\end{tabular}

Sumber: Data primer hasil olahan 2016 
Tabel 1.1 menunjukan frekuensi pilihan jawaban empat atau setuju sebesar 1924 (71,20 persen), kemudian diikuti pilihan jawaban tiga atau netral sebesar 453 (16,76 persen), pilihan jawaban lima atau sangat setuju 250 (9,25 persen), pilihan jawaban dua atau tidak setuju sebesar 74 (2,73 persen) dan terakhir pilihan jawaban satu sebesar 1 (0,03 persen).

$$
O P T=4,268+0.369(I N V) i+0.471(P E N) i+0,261(P P) i+e i
$$

Persamaan yang dihasilkan di atas disimpulkan pada tabel 4.15 berikut.

Tabel 1.2 Uji Coefficients

\begin{tabular}{|c|c|c|c|c|c|c|c|}
\hline Model & $\begin{array}{l}\text { Unstandardized } \\
\text { Coefficients }\end{array}$ & \multicolumn{2}{|c|}{$\begin{array}{c}\text { Standardized } \\
\text { Coefficients }\end{array}$} & $\mathbf{t}$ & Sig. & \multicolumn{2}{|c|}{$\begin{array}{c}\text { Collinearity } \\
\text { Statistics }\end{array}$} \\
\hline B & Std. Error & & & Tolerance & \multicolumn{3}{|c|}{ VIF } \\
\hline 1 & (Constant) & 4.268 & & 1.480 & 2.885 & .006 & \\
\hline INV & .369 & .076 & .554 & 4.862 & .000 & .489 & 2.043 \\
\hline LA & -.207 & .137 & -.225 & -1.513 & .138 & .286 & 3.494 \\
\hline PEN & .471 & .157 & .462 & 3.001 & .004 & .268 & 3.729 \\
\hline PP & 261 & .128 & .190 & 2.035 & .048 & .728 & 1.373 \\
\hline
\end{tabular}

a. Dependent Variable: $O P T$

Sumber: Data primer hasil olahan 2016

Konstanta (C) , Konstanta bernilai 4,268 dan signifikan memiliki arti jika semua variabel inventarisasi, legal audit, penilaian, serta pengawasan dan pengendalian sama dengan nol (tanpa ada variabel tersebut) maka variabel lain di luar model 61 masih berpotensi cukup besar mempengaruhi optimalisasi aset tetap (tanah dan bangunan) yakni terjadi kenaikan sebesar 4,26 persen.

Pengaruh inventarisasi aset terhadap tingkat optimalitas aset tetap (tanah dan bangunan). Dari hasil uji $t_{\text {tabel }} 3.8$ koefisien variabel inventarisasi aset mempunyai arah positif dan signifikan terhadap optimalitas aset tetap (tanah dan bangunan) dengan nilai koefisien regresi sebesar 0,369 yang menunjukan bahwa jika pelaksanaan inventarisasi aset meningkat sebesar 1 persen, maka secara rata-rata, optimalitas aset akan naik sebesar 0,36 persen dengan anggapan variabel lain tetap (cateris paribus). Hal ini membuktikan dengan adanya pelaksanaan inventarisasi meliputi pendataan, kodifikasi/labeling, pengelompokan dan pembukuan/administrasi yang baik maka akan memberikan prediksi adanya tingkat optimalitas aset tetap yang baik pula.

Pengaruh legal audit terhadap tingkat optimalitas aset tetap (tanah dan bangunan). Dari hasil uji $t_{\text {tabel }} 3.8$ koefisien variabel legal audit set mempunyai arah yang kurang signifikan terhadap optimalitas aset tetap (tanah dan bangunan) dengan nilai koefisien regresi sebesar $-1,538$ yang menunjukkan bahwa jika 
pelaksanaan legal audit tidak signifikan untuk itu tidak dianalisis secara mendalam agar tidak menimbulkan bias dalam penafsiran.

Pengaruh penilaian aset terhadap tingkat optimalitas aset tetap (tanah dan bangunan). Dari hasil uji $t_{\text {tabel }} 3.8$ koefisien variabel penilaian aset mempunyai arah yang positif dan signifikan terhadap optimalitas aset tetap (tanah dan bangunan) dengan nilai koefisien regresi sebesar 0,471 yang menunjukkan bahwa jika pelaksanaan penilaian aset meningkat sebesar 1 persen, maka secara rata-rata optimalitas aset akan naik sebesar 0,47 persen dengan anggapan variabel lain tetap (cateris paribus). Hal ini membuktikan dengan adanya penilaian yang baik dalam hal ini yang dilakukan oleh penilai independen (yang sertifikasi) dengan mencantumkan nilai aset tersebut dalam satuan rupiah maka akan memberikan prediksi adanya tingkat optimalitas aset yang baik pula.

Pengaruh pengawasan dan pengendalian aset terhadap tingkat optimalitas aset tetap (tanah dan bangunan) dengan nilai koefisien sebesar 0,261 yang menunjukkan bahwa jika pelaksanaan pengawasan dan pengendalian aset meningkat sebesar 1 persen, maka secara rata-rata optimalitas aset akan naik sebesar 0,26 persen dengan anggapan variabel lain tetap (cateris paribus). Hal ini membuktikan dengan adanya pelaksanaan pengawasan dan pengendalian yang baik melalui pengembangan SIMA (Sistem Manajemen Aset) maka akan memberikan prediksi adanya tingkat optimalitas aset yang baik.

\section{Hasil Wawancara dengan Informan}

Piet Uspessy, SE Kepala Bidang Aset di BPKAD Kabupaten Jayapura:

"Pada dasarnya telah dilaksanakan oleh para pengelola asset di setiap SKPD dan telah dilaporkan secara berkala, namun demikian masih terdapat berbagai permasalahan yang harus deibenahi secara seksama, terutama perlunya pengecekan kembali terhadap seluruh asset yang ada di SKPD untuk memastikan apakah asset-aset tersebut dokumennya tersimpan dengan baik". Disamping itu perlunya tindaklanjut terhadap hasil pengecekan yang dilaksanakan oleh BPK Perwakilan di Kabupaten Jayapura sebagai pihak auditor, karena banyak asset-aset yang berpindah tangan (bukan asset tetap) seperti mobil, motor, laptop, dan lain-lain, karena banyak yang bersangkutan telah dipindahtugaskan tetapi barangnya tidak dikembalikan ke SKPD pengelola asset tersebut". (wawancara, 24 Oktober 2016, pukul $08.00 \mathrm{WIT})$.

Supriyanto, SE selaku Pengelola Aset Setda Kabupaten Jayapura :

"Pengelolaan asset di Setda Kabupaten Jayapura telah optimal, data-data sudah masuk semua dan sudah dilaporkan ke BPKAD. Untuk keterangan ini dapat dilihat dari laporan kami dan bisa dicek Kartu Inventaris Barang (KIB), Buku Inventaris Barang, Kartu Inventaris Ruangan, dan lain sebagainya. Untuk asset Setda saya sendiri yang melaporkan ke BPKAD, kecuali 
kendaraan yang dibawa oleh para Pejabat yang sudah non job, itu biasanya langsung dari BPKAD dan pak Sekda". (Wawancara 24 Oktober 2016, pukul 09.00 WIT)

Rusli, SH pengelola Aset Dinas Pendidikan Kabupaten Jayapura :

"Aset Dinas Pendidikan Kabupaten Jayapura telah dicatat dengan baik, kalau diprosentasekan sekitar 85\% dan yang $15 \%$ belum tertata dengan baik karena adanya beberapa hal yakni asset yang rusak ringan, rusak berat, terutama yang hilang ini agak sulit untuk mendeteksinya, disamping itu yang berpindah tangan juga lebih susah lagi, karena bila yang bersangkutan dipindahtugaskan asset yang digunakan sebaga sarana kerja juga ikut pindah, itu belum lagi yang pensiun dan pindah tempat tinggal, lebih susah lagi untuk mencari yang bersangkutan. (Wawancara 24 Oktober 2016, pukul $11.00 \mathrm{WIT})$.

Ming Rotinsulu pengelola barang di Dinas Kesehatan kabupaten Jayapura :

Pencatatan inventaris di Dinas Kesehatan Kabupaten Jayapura telah dilakukan dengan baik sesuai dengan prosedur yang telah ditetapkan. Aset pengadaan tahun berjalan sudah sesuai dengan prosedur yakni setelah selesai pengadaan langsung dicatat di Buku Inventaris Barang, dibuatkan Nomor Barang serta penanggungjawab barang apabila langsung digunakan, sedangkan bila belum akan dimasukkan dalam Daftar Stock Barang. Hal ini juga memudahkan kami untuk pengecekan barang apabila suatu saat ada pemeriksaan dari BPK ataupun Inspektorat. Kami setiap mengeluarkan barang harus disiapkan dulu Berita Acara Serah Terima Barang, ini sebagai bukti pengambilan barang dan bukti jika suatu saat barang rusak atau hilang, maka pemegang barang yang harus bertanggungjawab. Disamping apabila SKPD berbelanja barang yang dapat dijadikan inventaris, perlunya penyesuaian dengan DPA agar tidaka terjadi kesalahan dalam pencatatan nantinya. (wawancara 24 Oktober 2016, pukul 11.30 WIT)

Budi selaku pengelola asset di Badan Pemberdayaan Masyarakat dan Kampung Kabupaten (BPMPK) Jayapura :

'Pengelolaan asset di BPMPK belum optimal, hal ini dikarenakan belum memiliki gudang yang representative, banyaknya barang yang harus dikelola, SDM pengelola yang masih sangat kurang. Saya sendiri harus mencatat, memeriksa, dan melaporkan semua inventaris yang ada di BPMPK. Sejak saya diserahi tugas sebagai pengelola asset, ternyata sudah banyak barangbarang yang berpindah tempat karena pemegang barang sudah pindah tugas di daerah lain. Sehingga pencatatan kami sangat sulit disebabkan yang bersangkutan tidak diketahui alamat lengkapnya, juga terkadang tidak bisa ditemui dengan berbagai alasan. Untuk itu melalui bapak ini kami mohon agar petugas pengelola barang ditambah, dan perlu ketegasan dari semua pimpinan agar mau mengambil asset-aset Negara yang sudah berpindah tangan tersebut".

Berdasarkan hasil wawancara dengan para informan tersebut dapat diketahui bahwa pengelolaan asset di beberapa SKPD sudah dilaksanakan, tetapi belum optimal. Hal ini yang menjadi masalah utama dalam pengelolaan asset di 
Pemerintah Kabupaten Jayapura. Untuk itu perlunya BPKAD melakukan pengecekan secara berkala terhadap inventarisasi barang milik pemerintah tersebut. Khusus untuk asset tetap pada umumnya sudah sangat baik, sehingga tidak ada kendala yang tidak dapat dicarikan solusinya, namun yang paling sulit adalah barang bergerak seperti mobil, motor, laptop, camera, dan barang-barang lain yang mudah dibawa ke mana saja. Masalah yang sering terjadi adalah barang yang digunakan rusak atau hilang tetapi tidak melaporkan kepada pengelola barang, sehingga setelah dilaksanakan pengecekan sulit untuk mencari barang bukti, sedangkan yang bersangkutan tidak bersedia mengganti barang yang rusak tersebut.

Dengan demikian hasil penelitian secara kualitatif di atas sejalan dengan pendapat Siregar (2004:519-520) yang menyatakan bahwa :

"Salah satu masalah utama pengelolaan barang (asset) daerah adalah ketidakterlibatan dalam pengelolaan data barang (asset). Ini menyebabkan Pemerintah Daerah akan mengalami kesulitan untuk mengetahui secara pasti asset yang dikuasi/dikelolanya, sehingga asset-aset yang dikelola pemerintah Daerah cenderung tidak optimal dalam penggunaannya. Kondisi di masa sekarang ini system informasi manajemen asset merupakan suatu sarana yang efektif untuk meningkatkan kinerja, sehingga transparansi kerja dalam pengelolaan asset sangat terjamin tanpa adanya kekhawatiran akan pengawasan dan pengendalian yang lemah.

\section{KESIMPULAN DAN SARAN}

\section{Kesimpulan}

Hasil penelitian ini membuktikan bahwa ada pengaruh yang positif dan signifikan antara inventarisasi aset terhadap tingkat optimalitas aset tetap (tanah dan bangunan) pada Pemerintah Daerah. Penelitian ini juga menjelaskan bahwa kurang ada pengaruh yang signifikan antara legal audit aset terhadap tingkat optimalitas aset tetap (tanah dan bangunan) pada Pemerintah. Hasil penelitian ini mengungkapkan bahwa ada pengaruh yang positif dan signifikan antara penilaian aset terhadap tingkat optimalitas aset tetap (tanah dan bangunan) pada Pemerintah Daerah. Penelitian ini membuktikan bahwa ada pengaruh yang positif antara pengawasan dan pengendalian aset terhadap optimalitas aset tetap (tanah dan bangunan) pada Pemerintah Daerah.

\section{Saran}

Jika dilihat dari signifikansi variabel yang paling berpengaruh terhadap tingkat optimalitas aset tetap (tanah dan bangunan) adalah inventarisasi. Karena memiliki signifikan yang paling kecil, maka pemerintah daerah Kabupaten Jayapura harus 
lebih meningkatkan system pendataan inventarisasi asset (tanah dan bangunan). Dalam hal ini pendataan, kodefikasi/labeling, pengelompokan dan pembukuan/administrasi sehingga dapat memberikan informasi yang tepat dalam penilaian, pengawasan dan pengendalian aset Kabupaten Jayapura.

Hasil dari tanggapan responden menunjukkan legal audit aset tidak berpengaruh terhadap tingkat optimalitas aset tetap (tanah dan bangunan). Tetapi alangkah baiknya variabel legal audit tetap diperhatikan secara khusus sebagai salah satu tahapan manajemen aset selain inventarisasi, tidak bisa dilakukan penilaian, pengawasan dan pengendalian, karena tahapan ini saling berhubungan dan terintegrasi. Legal audit aset pada pemerintah daerah Kabupaten Jayapura harus tetap diperhatikan karena menyangkut status penguasaan aset sehingga barang daerah tersebut dapat dipergunakan/dimanfaatkan secara optimal serta terhindar dari penyerobotan pengambil alihan atau klaim dari pihak lain.

Hasil dari tanggapan responden menunjukkan penilaian aset berpengaruh terhadap tingkat optimalitas aset tetap (tanah dan bangunan) pemerintah Kabupaten Jayapura. Oleh karena itu pemerintah daerah Kabupaten Jayapura harus melakukan penilaian atas aset yang dikuasai melalui konsultan penilaian yang independen untuk mengetahui nilai kekayaan maupun informasi untuk penetapan harga bagi aset yang ingin dijual.

Pengawasan dan pengendalian aset tetap yang telah dijalankan oleh pemerintah pada daerah Kabupaten Jayapura harus lebih ditingkatkan lagi dengan cara pemantauan, investigasi dan pengamanan terhadap aset tetap (tanah dan bangunan), sehingga penanganan aset termonitor jelas mulai dari lingkup penanganan hingga siapa yang bertanggungjawab menanganinya. Hal ini akan meminimalkan adanya kolusi, korupsi dan nepotisme dalam tubuh pemerintah daerah

\section{DAFATAR PUSTAKA}

Abdulah, Shardy, Razak dan Arman Abdul, Pakir, Abd Hamid Kadir, 2011, " The Caracteristics of Real Estate Assets Management Practice in the Malaysian Federal Government", Journal of Corporate Real Estate Vol 13. No 1, PP 16-35.

Aliasuddin, 2002, "Produksi Optimal dan RTS: Industri Besar dan Sedang di Provinsi NAD", Jurnal Riset Ekonomi dan Manajemen, vol. 2, No. 2, 2002, hal. 1-7. 
Antoh, Ester Agustina, 2012, "Manajemen Aset Dalam Rangka Optimalisasi Aset Tetap (Tanah dan Bangunan) Pemerintah Daerahndi Kabupaten Paniai", Tesis S2. Program pascasarjana UGM, Yoyakarta, (tidak dipublikasikan).

Bari, Muhammad, 2008, "Analisis Pengelolaan Aset Tanah dan BangunanPemerintah Kota Pontianak", Tesis. Program Pascasarjana UGM, Yogyakarta, (tidak dipublikasikan).

Bertovic, Kaganova dan Rutledge, 2002, Asset Management for Local Government, Local Government Reform Project (LGRP), The Urban Institute.

Boediono, 1999, Ekonomi Mikro, BPFE, Yogyakarta.

Dadson, James, and Ebenezer, Kobina, 2006, "Optimizing Land Asset Management in Ghana a Shared Responsibility and recipe for good Governance", Shaping the Change XXIII FIG Congress, Munich, Germany.

Ghozali, Imam. H, 2011, Aplikasi Analisis Multivariative Dengan Program IBM SPSS 19, Edisi 5, Badan Penerbit Universitas Diponegoro, Semarang.

Hanis Muhammad H, Trigunarsyah Bambang and Susilawati Connie, 2011, "The Application of Public Asset Management in Indonesia Local Government A Case Study in South Sulawesi Province", Journal of Corporate Real Estate Vol 13. No 1, PP 36-47.

Hidayati, Wahyu dan Harjanto, Budi, 2003, Konsep Dasar Penilaian Properti, BPFE, Yogyakarta.

Idrus, Muhamad, 2006,"Pengaruh Manajemen Aset terhadap Maksimalisasi Aset Tetap (Tanah dan Bangunan) Pemerintah Daerah (Studi di Kabupaten KolakaUtara)", Tesis. Program PascasarjanaUGM, Yogyakarta, (tidak dipublikasikan).

Ilham, Fadli, 2013, "Manajemen Aset Dalam Rangka Optimalisasi Aset Tetap (Tanah dan Bangunan) Pada Pemerintah Provinsi Sumatera Barat", Tesis. Program Pascasarjana UGM, Yogyakarta, (tidak dipublikasikan)

Mardiasmo, 2002, "Otonomi dan Manajemen Keuangan Daerah", Penerbit Andi, Yogyakarta.

Pakiding, Yanuarius, 2006, "Pengaruh Manajemen Aset Dalam Optimalisasi Aset Tetap (Tanah dan Bangunan) Pemerintah Daerah (Studi Kasus di Kabupaten Bantul)", Tesis. Program Pascasarjana UGM, Yogyakarta, (tidak dipublikasikan).

Hanis, H.M., Trigursyah, B., and Susilawati, C, 2011, "The Application of Public Asset Management in Indonesian Local Government," Queensland University of Technology, Brisbane, Australia

Husaini, 2005, "Maksimalisasi Keuntungan Lumbung Desa Modern Studi Kasus di Kabupaten Cirebon", Tesis S2, Program Pascasarjana UGM Yogyakarta (tidak dipublikasikan). 
Komite Penyusun Standar Penilai Indonesia. 2007, "Standar Penilai Indonesia". Jakarta

,Keputusan Menteri Keuangan KMK No 225/1971, KMK No 350/1994 tentang Aset Negara.

,Keputusan Menteri Dalam Negeri dan Otonomi Daerah Nomor 11 tahun 2001 diubah dengan Keputusan Menteri Dalam Negeri Nomor 152 Tahun 2004 tentang Pedoman Pengelolaan Barang Daerah.

,Keputusan Menteri dalam Negeri Nomor 12 tahun 2003 tentang Penilaian Barang Daerah.

Lewes District Council, 2005, Aset Management Plan.www:Lewes.gov.uk.

Lukman Azhari dan Akbar Roos, dan, 2010, "Manajemen Taman Milik Pemerintah Kota Bandung Berbasiskan Pendekatan Manajemen Aset", Jurnal Teoritis dan Terapan Bidang Rekayasa Sipil, Volume 17, Nomor 3, Desember 2010.

--------,Peraturan Menteri dalam Negeri Nomor 17 tahun 2007 tentang Pedoman Teknis Pengelolaan Barang Milik Daerah.

Peraturan Pemerintah Nomor 6 tahun 2006 tentang Pengelolaan Barang Milik Negara/Daerah.

Phelps, Alan James, 2009, "An Ekamination of the Relationship Between Rationale, Practice and Outcomes in Municipal Property Asset Management," International Development Department School of Government and Society University of Birmingham, A comparative Study of the UK and Russia.

Quertani, M.Z., Parlikad, A.K., and Mcfarlane, D, 2008, "Towards An Approach To Selected An Asset Information Management Strategy," International Journal of Computer Science and Application. Vol 5. No. 3b, PP 25-44.

Riduwan, 2009, “Metode dan Tehnik Menyusun Tesis”, penerbit Alfabeta Bandung.

Scharaven, Daan, Hartmann, Andreas and Dewulf, Geert, 2011, "Effective of infrastucture Assets Management: Chalallanges for Public Agencies", Journal of Corporate Real Estate Vol 1. No 1, PP 61-74.

Sekaran, Uma, 2006, Metode Penelitian Untuk Bisnis, Salemba Empat, Jakarta.

Siregar, Doli. D, 2004, Management Asset Srategi Penataan Konsep Pembangunan Berkelanjutan secara Nasional dalam Konteks Kepala Daerah sebagai CEO's pada Era Globalisasi dan Otonomi Daerah, penerbit PT Gramedia Pustaka Utama, Jakarta.

Singarimbun, Masri dan Effendi, Sofyan. 1989. Metode Penelitian Survey, Edisi Satu, PT Pustaka LP3ES, Jakarta.

Soeratno dan Lincolin Arsyad, 2008, Metodologi Penelitian untuk Ekonomi dan Bisnis, UPP AMP YKPN, Yogyakarta. 
Sugiyono,2013, "Metode Penelitian Kuantitatif Kualitatif dan R\&D", Penerbit CVAlfaBeta. Bandung.

Suharno, 2001, "Peningkatan Profesionalisme Penilai Pemerintah", Jurnal Survei Penilaian Properti, Vol 002. No 3, 330-338.

Surminah, Lin, 2008, "Manajemen Aset di Lembaga Litbang", Warta Kebijakan Iptek \& Manajemen Litbang, penerbit Papiptek-LIPI, Jakarta, 2008:77-94.

Thompson, Brian. E, 2010, "Achieving Asset Management Excellence", The Journal of Property and Asset Management is a periodic refereed journal published by the National property Management Association (NPMA), Vol 1. No 1.

--,Undang-Undang Nomor 1 Tahun 2004 tentang Perbendaharaan Negara.

---------,Undang-UndangNomor 17 Tahun 2003 tentang Keuangan Negara.

---------,Undang-Undang Nomor 22 Tahun 1999 tentang pengertian Otonomi Daerah

-Undang-Undang Nomor 32 dan 33 Tahun 2004 tentang Pemerintahan Daerah dan tentang Perimbangan Keuangan antar Pemerintah Pusat dan Pemerintah Daerah.

-,Undang-Undang Nomor 23 Tahun 2014 tentang Pemerintahan Daerah.

Wahyuni, Ary, (2011), "Pengaruh Manajemen Aset Terhadap Optimalisasi Pemanfaatan Aset Tetap Pemerintah Kabupaten Sumbawa Baraf', Tesis S2. Program Pascasarjana UGM, Yogyakarta, (tidak dipublikasikan).

Widarjono, A, 2009, Ekonometrika Pengantar dan Aplikasinya, Ekonisia Fakultas Ekonomi UII, Yogyakarta.

Wiyono, G, 2011, Merancang Penelitian Bisnis dengan Alat Analisis SPSS 17.0 \& SmartPLS 2.0, Unit Penerbit dan Percetakan STIM YKPN, Yogyakarta.

Zebua, Batzatulo, 2009, "Analisis Manajemen Aset (Tanah dan Bangunan) Pemerintah Daerah (Studi Kasus di Pemerintah Kabupaten Nias)", Tesis. Program Pascasarjana UGM, Yogyakarta (tidak dipublikasikan 